УДК 330

\title{
ЭКОНОМИКА КИБЕРСПОРТА В ПЕРИОД ПАНДЕМИИ КОРОНАВИРУСА
}

\author{
Батукаева Анжела Руслановна \\ старший преподаватель \\ Ятаев Али Ахмедович
}

ФГБОУ ВО «Чеченский государственный университет»

\begin{abstract}
Аннотация: В статье рассматривается вопрос о влиянии пандемии коронавируса на экономику киберспорта. Проведен анализ понятия киберспорта как экономического явления, изучены игроки рынка киберспорта и их доходы. Сделан вывод о том, что киберспорт является активно развивающейся спортивной индустрией и в него стоит инвестировать, даже в период пандемии коронавируса.
\end{abstract}

Ключевые слова: пандемия коронавируса, экономика киберспорта, инвестирование в киберспорт, виртуальная экономика, компьютерный спорт.

\section{THE ECONOMICS OF ESPORTS DURING THE CORONAVIRUS PANDEMIC}

\section{Batukaeva Angela Ruslanovna Yataev Ali Ahmedovich}

\begin{abstract}
The article discusses the impact of the coronavirus pandemic on the economy of eSports. The analysis of the concept of eSports as an economic phenomenon is carried out, the players of the eSports market and their incomes are studied. It is concluded that eSports is an actively developing sports industry and it is worth investing in, even during the coronavirus pandemic.

Key words: coronavirus pandemic, eSports economy, investing in eSports, virtual economy, computer sports.

Именно разработчики игр дали старт появлению понятия киберспорт. И данная отрасль сформировалась не только потому, что человек играет в игры, а благодаря стриминговым платформам, которые транслируют игры в режиме




\section{МОЛОДЕЖНАЯ НАУКА КАК ФАКТОР И РЕСУРС ИННОВАЦИОННОГО РАЗВИТИЯ}

онлайн, дополнением к этому является киберспортивные команды, которые ничем не уступают командам в традиционном спорте, например, у них есть свои спонсоры, болельщики и так далее. Все это привело и приводит на сегодняшний день к потенциальным инвесторам.

Надо отметить, что Россия в 2001 году стала первой в мире, которая признала его официальный статус. На сегодняшний день рынок киберспорта в России составил более 45 млн. \$.

Пандемия коронавируса стимулирует развитие не только платформ для проведения онлайн-конференции или сервисов для доставки еды, но и киберспорта. И особенно сейчас, когда вопрос проведения традиционных видов спорта ещё не решен до конца, компьютерный спорт стремительно привлекает внимание спонсоров и простых людей по всему миру.

Из-за пандемии коронавируса экономика киберспорта столкнулась с такой же проблемой, что и традиционный вид спорта: все запланированные ивенты на начало 2020 года, перенесены на осень или в онлайн. К примеру, один из крупнейших турниров по шутеру Counter-Strike: Global Offensive IEM Katowice 2020 (16 команд и \$500 000 призовых) - впервые в истории провели без публики: в арене Spodek, вместимостью 11500 человек. Следом киберспортивная ассоциация ESL Pro League (24 команды и \$750 000 призовых) принимает решение о переносе всех оффлайн матчей в онлайн. Также аналогичное решение принимает франшизная лига FLASHPOINT (12 команд и \$1 млн призовых).

Был отменен один из самых ожидаемых турниров ESL One Los Angeles 2020 [2] (\$1 млн призовых). Многие клубы уже успели прибыть в США ради этого турнира, поскольку его результаты могли кардинальным образом изменить расстановку сил в мировом рейтинге и повлиять на то, какие команды попадут на чемпионат мира по Dota 2 - The International, где речь шла о гораздо огромных суммах $(\$ 40,018,195)$. К примеру, ESL потерял около сотни тысячи долларов на возврате билетов, аренде и оборудовании площадок, помощи игрокам, уже приехавшим на место проведения турнира. С тех пор проводятся онлайн турниры, поделенные на регионы (Европа/СНГ, Америка, Азия и т.д.). С тех пор количество зрителей стремительно растет.

Благодаря тому, что киберспорт сам по себе ориентирован на онлайн, он гораздо более устойчив к условиям пандемии, чем остальная спортивная индустрия. Офлайн-турниры для киберспорта не играют огромную роль в его развитии. Если на обычные стадионы приходят десятки тысяч людей, то 
аудиотория транслирования популярных турниров измеряется миллионами. К примеру, в 2019 году турнир Epicenter Major по игре Dota 2 собрал 46 миллионов просмотров на различных платформах (без учета китайской аудитории) и 15 миллионов уникальных пользователей. А текущие трансляции, в период изоляции, ставят новые рекорды.

Так, один из недавних матчей международной серии ESL Pro League в пиковый момент смотрели 489000 человек. Для сравнения: за финалом прошлого сезона следили 370000.

При этом растет не только зрительская аудитория, но и число играющих: за март аудитория Dota 2 [3] выросла на 7,68\%. Среднее число онлайн-игроков в Counter-Strike: Global Offensive по итогам марта составило 671000 человек (из них 90 тысяч - игроки из России) — это на 127000 (23,36\%) больше, чем в феврале.

Казалось бы, с такими цифрами можно легко сказать, что годовой объем киберспорта в 2020 будет гораздо выше, чем в 2019 году. Но точных результатов пока никто не может сказать (рис. 1., рис. 2).

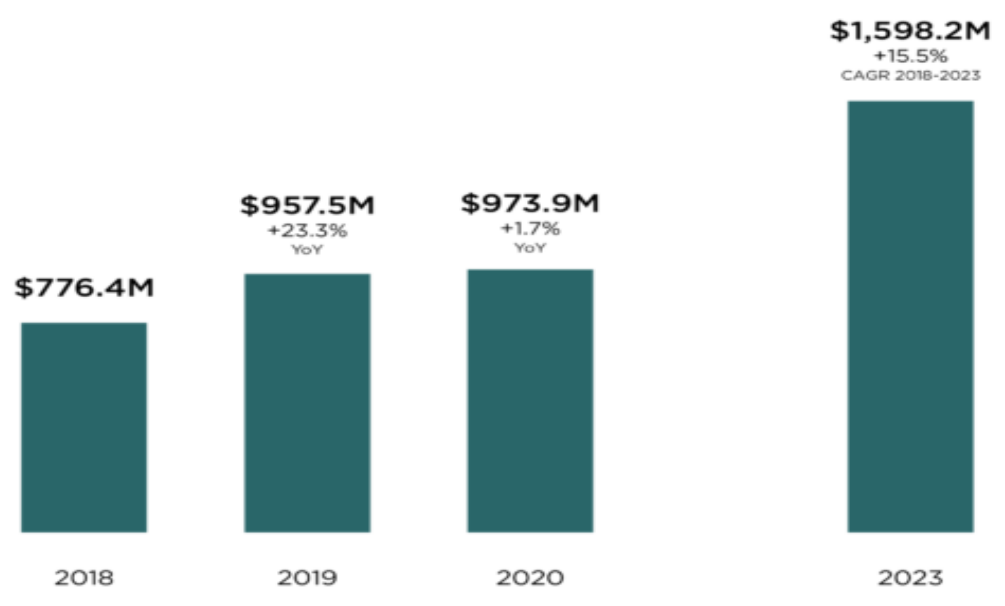

\section{Рис. 1. Прогноз предполагаемой выручки мирового киберспорта}

Исследовательская компания Newzoo[4] из-за коронавируса уже 3 раз за год меняет итоговую выручку по рынку киберспорта на 2020 год. Отметим, что цифры в \$1,1 млрд Newzoo указывала в февральском прогнозе, но уже в апреле снизила их до $\$ 1,059$ млрд. После чего в июле компания снова сделала перерасчет и назвала предполагаемой выручкой мирового киберспорта сумму в размере $\$ 974$ млн. Это объясняется тем, что зрители практически не посещают 
мероприятия из-за пандемии. Поэтому, продажи билетов и товаров в 2020 принесут всего $\$ 52,5$ млн, а не $\$ 121,7$ млн, как говорилось в февральских отчетах.

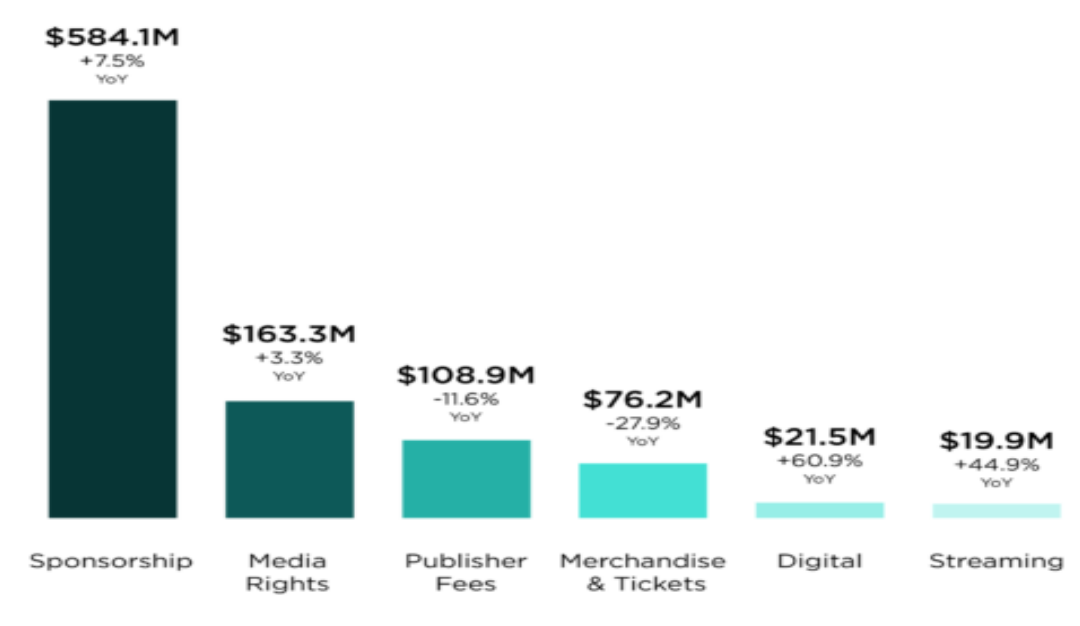

\section{Рис. 2. Источники доходов в киберспорте}

Как можно заметить основной доход идет от спонсорства. Такие гиганты, как Shell, Adidas или Intel активно спонсируют киберспортивные мероприятия, а также являются спонсорами многих именитых команд. Также спонсорами киберспортивных команд уже становились ВТ, Kia Motors, Louis Vuitton, Xiaomi и многие другие компании. Теперь же эта область становится еще более привлекательно, когда другие сферы переживают спад.

Можно смело говорить, что киберспорт является активно развивающейся спортивной индустрией [1]. В критической ситуации он показал себя достойно: подстроился под рекламодателей и спонсоров, быстро адаптировался сам.

\section{Список литературы}

1. Спорт, который сильнее вируса: как спортивная индустрия переходит на онлайн-форматы https://www.forbes.ru/biznes/397427-sport-kotoryy-silneevirusa-kak-sportivnaya-industriya-perehodit-na-onlayn-formaty (дата обращения 15.12.2020)

2. Streamlabs \& Stream Hatchet Q1 2020 Live Streaming Industry Report https://blog.streamlabs.com/streamlabs-stream-hatchet-q1-2020-live-streamingindustry-report-9630bc3e0e1e (дата обращения 16.12.2020) 
3. Обзор киберспортивного маркетинга: сегменту удалось показать рост в пандемию https://www.sostav.ru/publication/kibersport-i-pandemiya-prognozy-irealnost-2020-46036.html (дата обращения 15.12.2020)

4. Newzoo Adjusts Esports Forecast Further in Wake of the Ongoing COVID-19 Pandemic https://newzoo.com/insights/articles/esports-market-revenues2020-2021-impact-of-covid-19-media-rights-sponsorships-tickets/ (дата обращения 16.12.2020)

(C) А.А. Ятаев, А.Р. Батукаева,2020 